\title{
VIRTUAL GRAPHIC REPRESENTATION OF CONSTRUCTION EQUIPMENT FOR DEVELOPING A 3D EARTHWORK BIM
}

\author{
Sungwoo MOON ${ }^{\mathrm{a}}$, Jongwon $\mathrm{SEO}^{\mathrm{b}}$ \\ ${ }^{a}$ Department of Civil and Environmental Engineering, Pusan National University, South Korea \\ ${ }^{b}$ Department of Civil and Environmental Engineering, Hanyang University, South Korea
}

Received 15 Nov 2016; accepted 21 Jun 2017

\begin{abstract}
BIM provides a visualization of the construction design that allows a construction manager to review the construction process and the information that is associated with the progress. BIM is usually applied to modeling structural objects with parametric geometry where the sequence of process can be predefined. However, BIM technology can also be applied to objects with irregular shape where parametric modeling is not possible such as earthwork topography based on TIN (Triangular Irregular Network). The objective of this research is to develop a 3D earthwork BIM methodology and provide a graphic simulation that is capable of assisting construction equipment operators during excavation work. The 3D earthwork BIM presents a modeling technique that involves integrating hardware and software technologies. This combination of technologies is used to represent the actual excavator configuration in a $3 \mathrm{D}$ virtual environment. When it is applied to actual excavation work, it was proved that the 3D earthwork BIM could synchronize the virtual excavator configuration with the actual excavator configuration during excavation work in real time.
\end{abstract}

Keywords: BIM, earthwork operation, construction equipment, geographical modeling, excavator, graphic simulation.

\section{Introduction}

Building Information Modeling (BIM) is a 3D graphic simulation of a construction design. BIM provides a visualization that allows a construction manager to review the construction process and the information associated with the progress. Azhar (2011) stated that this technology offers a digitally constructed environment that can be applied in the design and construction stages. BIM stores the attributes of the dimension, volume, material type, and duration of its structural components in a database. During the design stage, these attributes are used to establish budgets and estimate construction durations. During the construction stage, these attributes are updated to indicate the progress of the construction operation.

A construction manager can utilize the information from BIM to communicate with the owner and the contractor during the construction process. Kim and Lee (2014) argued that the construction manager could store information on the life cycle of the construction project and reuse the information in future projects. From this perspective, a 3D graphic simulation provides valuable information for construction planning prior to actual construction (Bedrick, Davis 2012), and stores actual data during construction. These functional benefits allow BIM to be used as a management tool throughout the construc- tion life cycle of structural facilities, such as buildings, bridges and industry infrastructures.

Although BIM offers many benefits, the technology is usually applied to modeling definite structural objects with parametric geometry where the sequence of process can be predefined. After the sequence is fixed, the flow of installing structural components can be easily identified and integrated into a 3D graphic simulation. The ease of modeling based on parametric geometry has limited the application of BIM to structural facilities (Moon 2015). However, BIM technology can also be applied to objects with irregular shape where parametric modeling is not possible such as earthwork topography based on TIN (Triangular Irregular Network) (Lee et al. 2014). This application is challenging because the earthwork BIM has to simulate unstructured processes and object data (Jo et al. 2012). For example, the sequence of excavation is very difficult to be predefined because the task is dependent on the varying site conditions and the equipment operators' heuristic decisions. In this study, BIM is extended to include non-parametric and irregular-shape objects that are encountered during earthwork operations.

Machine guidance and/or control technology has been developed to enhance the performance of construc-

Corresponding author: Jongwon Seo

E-mail: jseo@hanyang.ac.kr 
tion equipment, such as excavator (Leica Geosystems 2016; Prolec Ltd. 2016; Topcon 2016). Such technology requires models for earthwork equipment and earthwork design (finalized shape of earth after earthwork construction) as well as the original topography before construction. Autonomous control of earthwork equipment requires same kind of models to guide the equipment for the completion of the required job (Seo et al. 2011). The real-time tracking and modeling of equipment configuration is also required for machine guidance and autonomous control of earthwork equipment. Yamamoto et al. (2009) developed an autonomous machine control so that an excavator could execute digging and loading grounds under limited conditions. In this approach, the equipment configuration was estimated using potentiometers installed on the hinges of the excavator sections of the boom, arm, and bucket, while the position of the machine was determined using the Global Positioning System (GPS). Azar et al. (2015) applied computer-vision technology for estimating the excavator configuration using low-cost markers installed on the sides of the excavator sections. This approach required a camera to be set up to monitor the movement and to measure the angles of the excavator sections. However, the camera could lose sight of the excavator because the construction equipment was constantly moving to dig and load excavated soil onto a dump truck.

This study is unique in that it presents functional and data requirement for establishing a 3D earthwork BIM technique that offers a flexible visualization of the earthwork operation in action. That is, this approach relates the movement of an excavator in relation with a 3D digital map to generate visual and numerical information for the operation of the equipment. The concept of BIM can enhance data management and functionality to assist equipment operators during an earthwork operation. This agrees with the perspective of Jo et al. (2012) who argued that the earthwork BIM approach provided a life cycle management tool through a 3D information modeling of cutting and embanking in the earthwork operation.

The objective of this research is to develop 3D earthwork BIM technology by applying the concept of BIM to excavation work at a construction site. This study presents a 3D graphic simulation environment to describe the movement of construction equipment and changes in the geographical terrain in a 3D digital space during excavation work. In this study, the 3D earthwork BIM presents a modeling technique that integrates geographical modeling and equipment modeling. This combined effort represents the actual excavator configuration in a 3D graphic simulation environment. In the field experiment using actual excavation work, the 3D earthwork BIM demonstrated its capability of synchronizing a virtual excavator configuration with an actual excavator configuration in real-time.

The study is executed in three parts. First, digital maps are defined to show the original and planned ground surfaces of the construction site. These digital maps are constantly updated to show the deformation on the ground surface during excavation work. Second, 3D graphic models are defined to show the equipment configuration of an excavator. Sensory devices are used to understand the configuration of the excavator. GPS-RTK (Real Time Kinematic) devices are used to keep track of the position and orientation of the construction equipment. Third, the 3D earthwork BIM is tested in real excavation work to evaluate its applicability.

\section{Overview of a 3D earthwork BIM}

The 3D earthwork BIM is defined as a digital environment where the movements of construction equipment are simulated in a 3D digital space. This 3D earthwork BIM synchronizes the movement of actual construction equipment with that of graphical construction equipment. The uniqueness in this approach is that the $3 \mathrm{D}$ modeling technique in the BIM technology is utilized for representing: 1) the movement of construction equipment and 2) changes in the geographical terrain in a 3D digital space during excavation work. First, the 3D model of construction equipment can be viewed in a higher flexibility than the conventional machine guidance and/or control technology. For example, the construction equipment can be shown in different viewpoints of 3D as well as X, Y, and $\mathrm{Z}$ sections. Second, the geographical ground condition can be viewed in a more realistic condition. For example, the surface of ground surface changes as excavation work progresses to show actual ground conditions after digging.

\section{Preparation of digital maps}

The 3D earthwork BIM shows the graphic simulation of construction equipment on a ground surface at a construction site. Therefore, the ground surface should be simulated to show the deformation of the ground surface while the excavator is digging. In the 3D earthwork BIM environment, a digital map represents the original and the planned ground surfaces in the earthwork operation. Therefore, in the graphic simulation, the digital map should be prepared as both original and planned maps for the specific construction site. These maps can be uploaded onto the 3D earthwork BIM and updated to show the deformation of the ground surface.

\subsection{Original digital map}

An original digital map is a representation of geographical spatial data in discrete points on the ground surface using a digital format. Digital maps can be acquired by using laser scanners, drones, or any other compatible surveying methods (Seo et al. 2015). Or they can be downloaded from government organizations, such as the United States Geological Survey (USGS) or the National Geographic Information Institute (NGII) in Korea. Two types of digital maps were reviewed for selection in 
this study: triangular irregular network (TIN) and digital elevation model (DEM) (Burrough et al. 2015). TIN method represents the elevation of a geographical surface and the characteristics of complex geographical terrains using the corners of irregular triangles. This method uses small digital data. Since the triangle has different lengths, a steep surface is shown with small triangles, while a plane surface is shown with large triangles.

DEM method represents the elevation of a ground surface using the corners of regular rectangles. This method is less suitable to show the characteristics of complex geographical terrains compared with the TIN method. However, the regular rectangles allow for a data structure that is simpler than that of the TIN method. This simplicity provides ease in analyzing and manipulating geographical data; it is frequently used in developing engineering solutions in civil engineering (Sharma et al. 2010; WMO 2012).

In a 3D earthwork BIM, DEM method was used to represent the deformation of the ground surface at a construction site. When DEM method is applied, the distance of the rectangles can be adjusted to suit the requirement in any application. Due to these strong benefits, this study employed DEM method in developing the 3D earthwork BIM. In this study, the distance of the rectangles was set up in an interval of $10 \mathrm{~cm}$.

\subsection{Planned digital map}

An original digital map shows the original status of the ground surface before excavation at the construction site and provides $3 \mathrm{D}$ geographical information on the current status of the construction site. Prior to actual implementation in the 3D earthwork BIM, a planned digital map should be prepared to show the area and depth to excavate at the construction site.

Figure 1 shows a digital map of original and planned ground surfaces. The planned digital map is represented

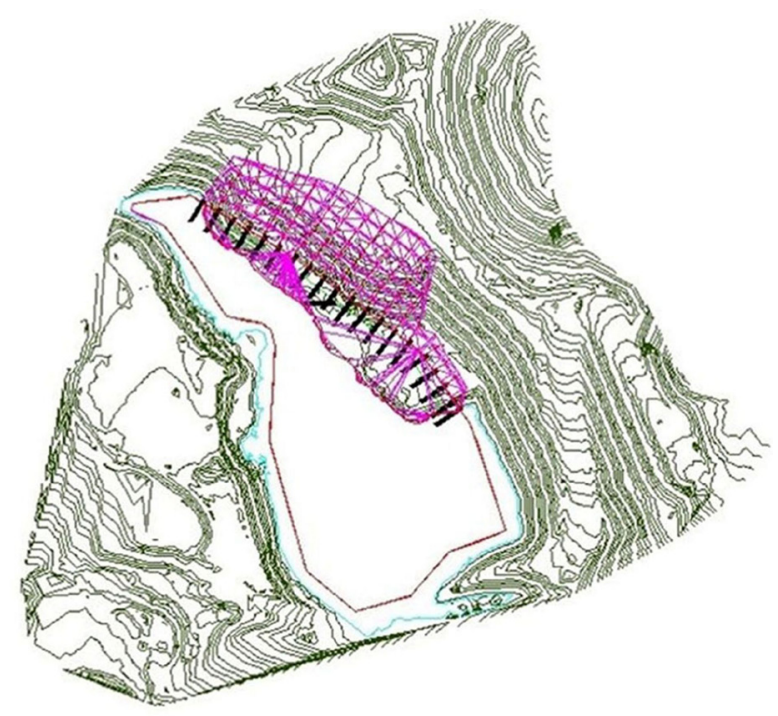

Fig. 1. Digital map of original and planned ground surfaces by TIN. In Figure 1, the original ground that is not affected by construction operation is represented along with the planned digital map as 3D contour lines.

In the 3D earthwork BIM, the digital map is also used to indicate the planned ground surface compared with the actual ground surface. The actual ground surface shows the deformation in real time during an excavation. Showing the deformation requires a constant update of the digital map. Three types of digital maps are used in the simulation: the original, the planned, and the actual. The original digital map shows the natural ground surface before the excavation. The planned digital map shows the target depth of the excavation. The actual digital map shows the as-is depth of excavation on the ground surface.

\section{Modeling of equipment configuration}

Vehicle configuration modeling involves software and hardware development. Software development involves drawing equipment section images in a 3D digital space and building an object hierarchy. Hardware development involves using inertial measurement unit (IMU) sensors and position data from a GPS-RTK device. The kinematic equation is used to estimate equipment configurations. This section discusses the details of the key components used in vehicle configuration modeling for the $3 \mathrm{D}$ earthwork BIM.

\subsection{Equipment section images}

The excavator consists of five sections: a lower body, an upper body, a boom, an arm, and a bucket. Each section is graphically modeled to show the vehicle configuration. Figure 2(a) shows the 3D models of the excavator sections. These sections are graphically built to scale. The sections are modeled individually and then combined to show the equipment configuration (Fig. 2(b)). These sections are manipulated to show the equipment configuration during the graphic simulation of the earthwork operation.

The excavator sections are stored in a library as a block, and can be withdrawn for graphic simulation. The simulation of equipment configuration includes the articulation of the boom, arm, and bucket. During the graphic simulation, the equipment configuration constantly changes to show the excavator digging at the ground surface. The simulation also includes rotation of the upper body and movement of the lower body around the excavation area.

\subsection{Object hierarchy for equipment sections}

The 3D graphic simulation is executed in a hierarchy of objects. Each object has values for position, rotation, and scale. A hierarchy can be built and controlled using the parent-child relationship. Table 1 shows the objects that are built for the 3D earthwork BIM. The excavator is divided into five sections: lower body, upper body, boom, 

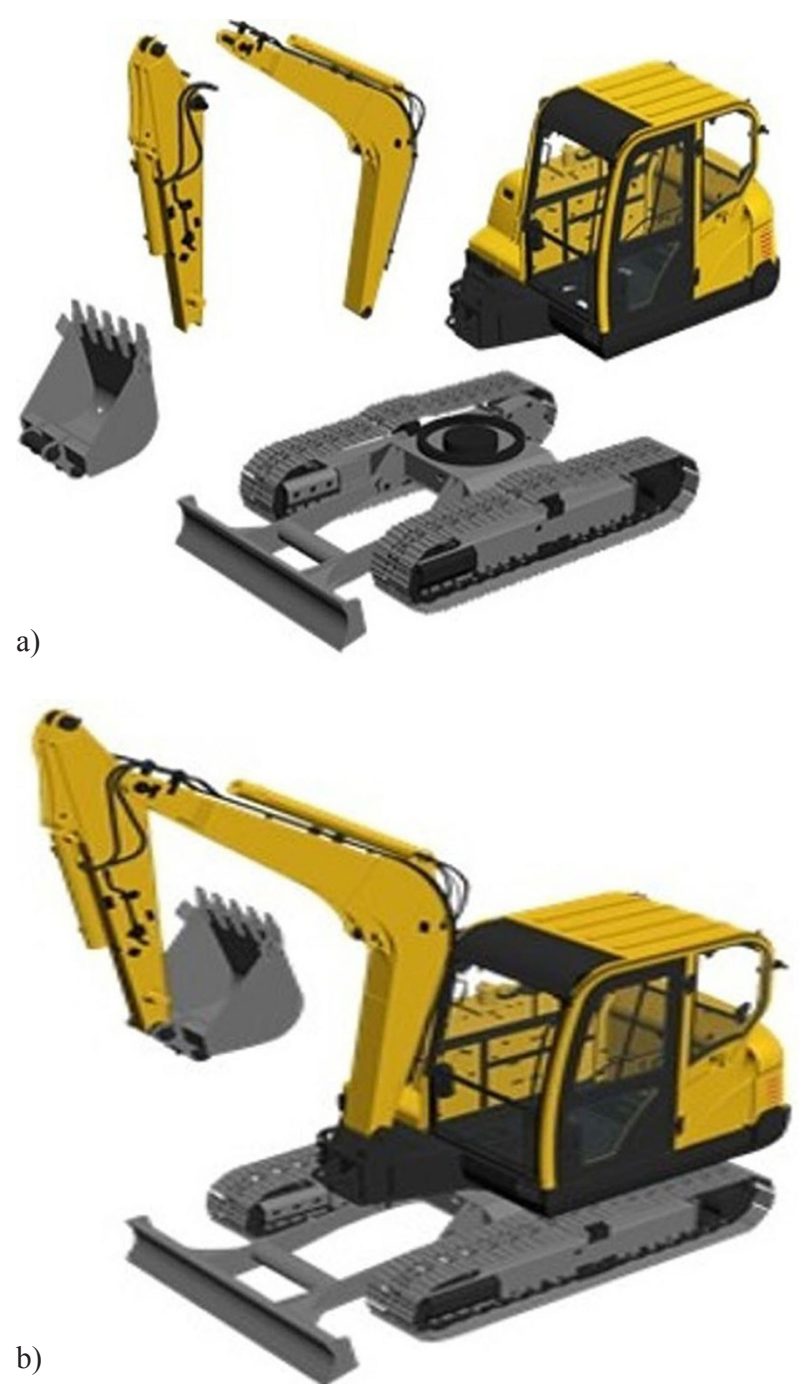

Fig. 2. a) 3D models of the excavator sections; b) equipment configuration

arm, and bucket. The lower and upper bodies are in the same level of the hierarchy so that they can rotate independently in the graphic simulation. The upper body is given the parent relationship to the boom, arm, and bucket so that these components can move together as the upper body rotates.

\subsection{Equipment configuration}

Kinematic calculations are required to constantly simulate the configuration of an excavator during excavation work. This equation estimates the end tip position of articulated equipment (Groover 1986). For example, the kinematic calculation is used to estimate the coordinate position of a bucket tip. The basis point in the calculation is the hinge of the boom that is attached to the body of the excavator; it is given a xyz coordinate value of $(0,0,0)$. The calculation requires the lengths of the boom, arm, and bucket, and the angular values between any two excavator sections (Fig. 3). In Figure 3, L1, L2, and L3 indicate the lengths of the boom, arm, and bucket, respectively, while $\theta 1, \theta 2$, and $\theta 3$ indicate the angles of the boom, arm, and bucket, respectively.

The angular values are obtained using the sensory data from the IMU sensors developed in this study. The IMU sensors use three types of sensory devices: gyroscope, accelerometer, and gravity meter. Figure 3 shows the positions of these sensors. The IMU sensors generate the angles between any two excavator sections. In this study, the IMU sensors were attached to the surface of the excavator components that were parallel to the line of the two hinges. The kinematic calculation uses the straight line from the center of the hinge to the center of another hinge. Note that the sensory angular value for bucket is different from the actual angular value (Azar et al. 2015). In this study, this difference is compensated

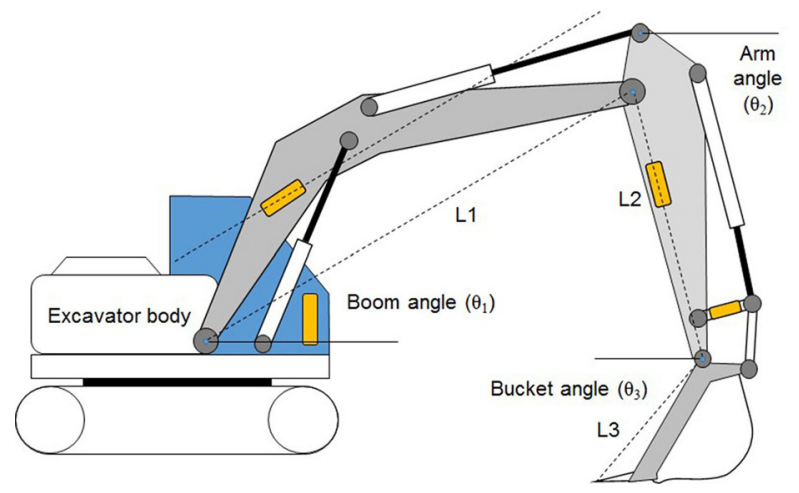

Fig. 3. Installation of IMU sensors on the excavator sections

Table 1. A hierarchy of objects for the 3D model components

\begin{tabular}{|c|c|c|c|}
\hline Object level & 3D object & Description & Remarks \\
\hline 0 & Backho & Whole excavator body, including the boom, arm, and bucket & \multirow{6}{*}{ 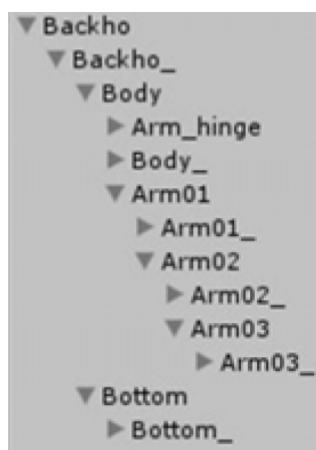 } \\
\hline 1 & Bottom_ & Lower excavator body & \\
\hline 1 & Body_ & Upper excavator body & \\
\hline 2 & Arm01_ & Boom & \\
\hline 3 & Arm02_ & Arm & \\
\hline 4 & Arm03_ & Bucket & \\
\hline
\end{tabular}


using an offset function in the program module of the kinematic calculation.

This study assumed that the ground surface was flat and level to the sea surface. That is, this study assumed that the excavator was positioned on a leveled surface. Actually, when doing excavation work, an excavator operator usually flattens the ground surface on which the excavator is positioned. This assumption makes the simulation simpler and more practical. Otherwise, the kinematic calculation involves more rigorous efforts to calculate the exact position of the excavator sections.

\subsection{Vehicle position and orientation}

The GPS-RTK technology is used for locating the excavator. The GPS-RTK technology increases the precision of the GPS position data. In this position identification system, the base station receives encoded signals of GPS data from at least four satellites in the Global Navigation Satellite System (GNSS). Base station is installed on the reference point which is created in Transverse Mercator coordinate system. Base station converts real-time GPS coordinates into TM to be compared with reference point coordinate for error calculation, and the information is sent to GPS controller for calibration of accurate position of the excavator. In this study, two antennas are installed on the body of an excavator to identify the realtime equipment position. The two antennas are for obtaining azimuth by calculating the horizontal angle from the north direction. The calculated azimuth is linked with position information (roll, pitch, yaw) for each axis of the excavator obtained from gyro sensor in order to calculate precise orientation and position information of the excavator in real-time. The orientation and position information together with IMU sensor information (Fig. 3) are sent to the machine guidance terminal for calculating final bucket position through excavator TM coordinate converting and relative bucket position calculation modules.

In this study, the position information and the azimuth data in the GPS-RTK are generated in the form of National Marine Electronics Association (NMEA) data (NGII 2015). The excavator position information uses GGA protocol and the azimuth data uses HDT protocol. Since the original and planned digital maps are in the DEM format, the NMEA data is converted into xyz position (TM) data in the DEM format. This converted local position data is used to track an excavator moving around an earthwork operation.

\section{Prototyping a 3D earthwork BIM environment}

The digital map and equipment configuration are combined to prototype a 3D earthwork BIM environment. The digital map provides information about the ground surface, while the equipment configuration provides information about the vehicle operation and position. Combining the information requires an integration of hardware and software, and produces a 3D graphic simulation to match the actual equipment configuration while performing excavation work. This integration makes the 3D earthwork BIM different from the general BIMs that are applied to predefined structures. This section discusses the system structure of the 3D earthwork BIM and its application to actual excavation work.

\subsection{System structure}

The 3D earthwork BIM consists of four modules: graphic simulation, an IMU sensor, a database, and data communication (Fig. 4). First, a graphic simulation module is built using a game tool. This module provides a flexible

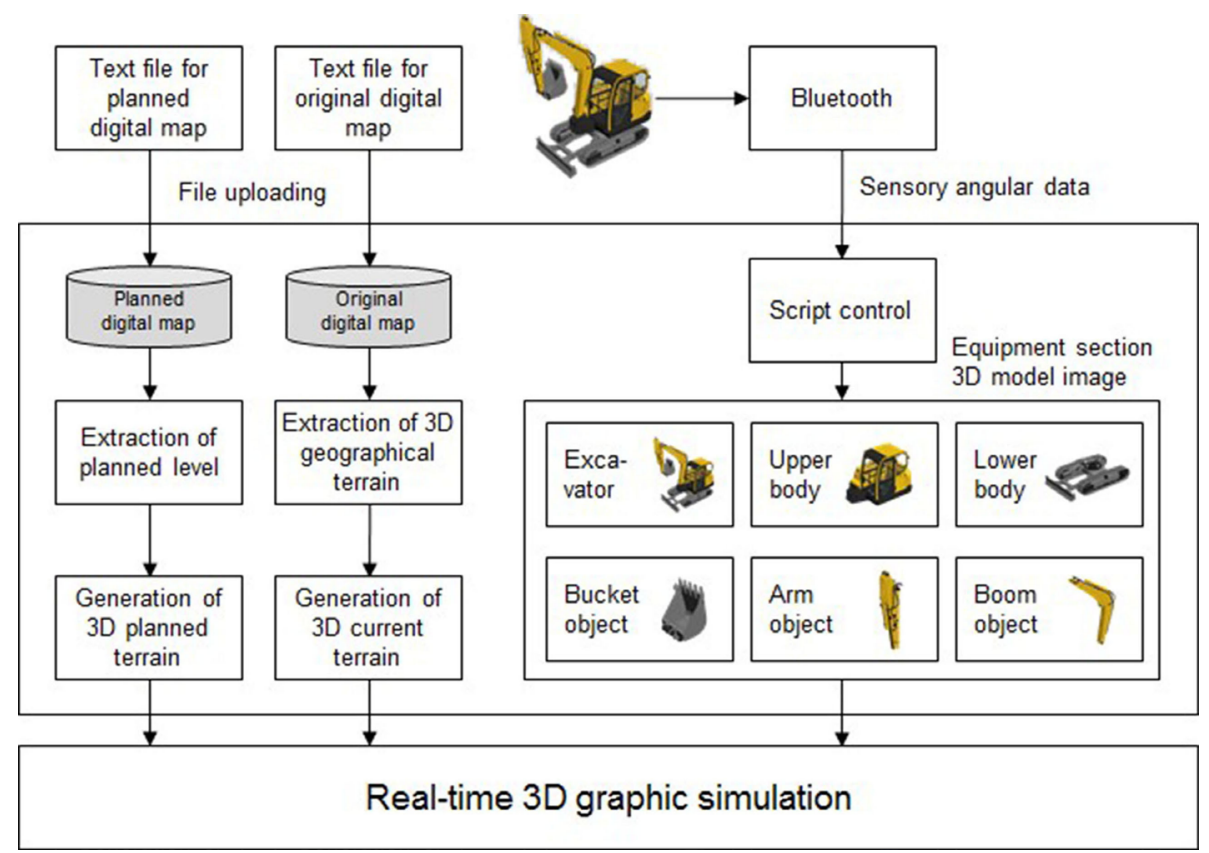

Fig. 4. System structure 
manipulation of the ground surface and the equipment configuration. Second, the IMU sensor module measures the angles of the equipment sections. The sensory data are used in the kinematic equation. Third, the database module stores the original and planned digital maps. The xyz coordinate data in these digital maps are used to indicate the equipment's position, as well as the elevation of the ground surface. The digital maps are constantly updated to show the deformation of the ground surface during excavation. Finally, the communication module transmits the sensory data to the script control using the Bluetooth 4.0 standard. This Bluetooth technology consumes low energy and assures continuous connection for data communication (Bluetooth SIG Inc. 2016).

The script in the game tool controls the angular positions of the excavator sections (boom, arm, and bucket). The 3D model images of the equipment sections are used to show equipment configuration and movement. The final output of the 3D earthwork BIM is displayed on a computer screen during excavation. The computer screen can also show the graphic simulation of an excavator digging the ground surface and loading the excavated soil onto a dump truck.

\subsection{Matching actual and virtual configurations}

In this study, the prototype of a 3D earthwork BIM was applied to real excavation work. The goal of this field experiment was to determine if the virtual equipment configuration of a 3D earthwork BIM could be synchronized with the actual equipment configuration of an excavator during excavation work. Figure 5(a) shows the equipment configuration at an actual site during excavation work, while Figure 5(b) shows a graphical image in the 3D earthwork BIM. As the actual excavator digs the ground surface, the 3D earthwork BIM represents the equipment configuration of the actual excavator in a 3D space. The deformed ground surface is shown in Figures 5(c) and 5(d). The views of the deformation of the ground surface provide information to the equipment operator about the current depth and the planned depth of the excavation.

Figures 5(c) and 5(d) show the front and side views of the deformed ground surface during the actual excavation work in this study. The indented area in these figures shows the cross-section of the excavated area. In Figure 5(c), the cross-section shows the depth and the width of excavation. In Figure 5(d), the cross-section shows the depth and the length of excavation. The difference between the depth in the actual excavation and in the virtual 3D graphic simulation serves as a yardstick for measuring whether the 3D graphic simulation is accurately describing the actual deformation of ground surfaces during excavation work.

\subsection{Measurement differences in actual and virtual configurations}

The virtual equipment configuration of a 3D earthwork BIM should match the actual equipment configuration

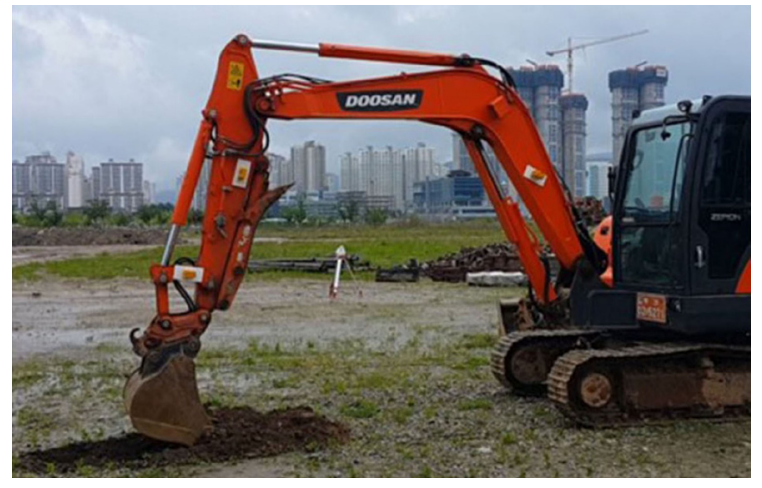

a)

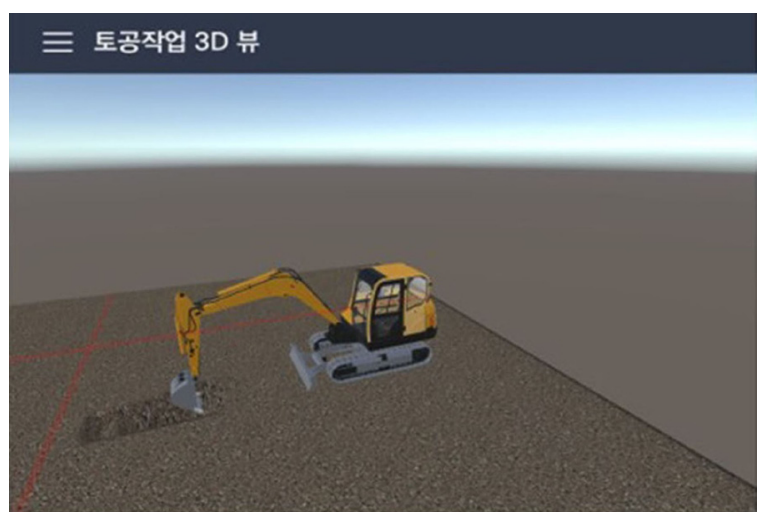

b)

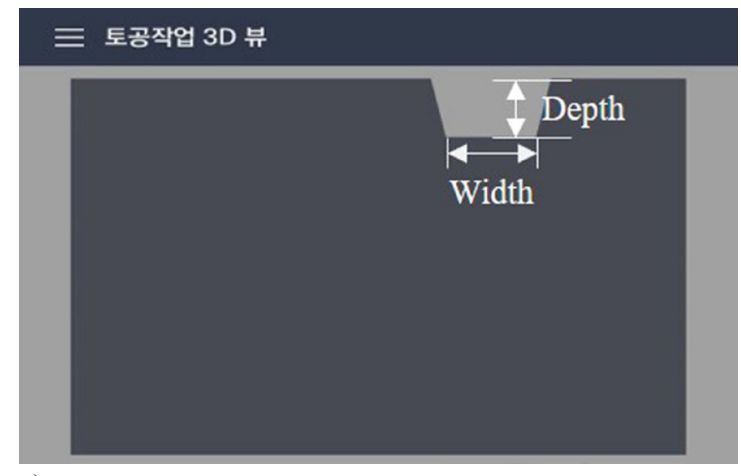

c)

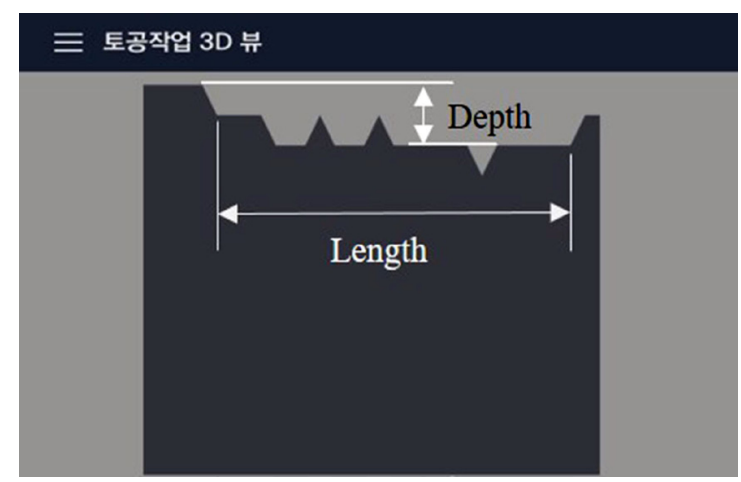

d)

Fig. 5. a) The equipment configuration at an actual site during excavation work; b) graphical image in the 3D earthwork BIM; c) and d) front and side views of the deformed ground surface during the actual excavation work 
Table 2. Comparison of actual and measured angles

\begin{tabular}{|c|c|c|c|c|c|}
\hline Evaluation criteria & Actual & Virtual & Difference & \multicolumn{2}{|l|}{ Remarks } \\
\hline $\begin{array}{l}\text { Bucket tip position from } \\
\text { the boom hinge }(\mathrm{x}, \mathrm{y})\end{array}$ & $(345,-18)$ & $(336,-6)$ & $(\Delta 9, \Delta 12)$ & \multirow{4}{*}{ Horizontal level to the boom hinge } & \multirow{3}{*}{ Excavator } \\
\hline Boom angle $\left(^{\circ}\right)$ & 31.8 & 33.8 & -2.0 & & \\
\hline \multirow[t]{2}{*}{ Arm angle $\left({ }^{\circ}\right)$} & \multirow[t]{2}{*}{-32.8} & \multirow[t]{2}{*}{-32.3} & \multirow[t]{2}{*}{0.5} & & \\
\hline & & & & & \\
\hline Bucket angle $\left({ }^{\circ}\right)$ & -115.8 & -118.4 & -2.6 & Ground level & \\
\hline
\end{tabular}

during excavation work to generate visual information for equipment operators. In this field experiment of real excavation work, the virtual equipment configuration was compared with the actual equipment configuration to understand the accuracy of the 3D earthwork BIM. The overall performance of the 3D earthwork BIM was evaluated using the accuracy of the predicted position of the bucket tip.

Table 2 shows that the angles are within $\pm 3^{\circ}$ in precision. The difference in the measurement of lengths was calculated using a forward kinematic equation. When the angles of the boom, arm, and bucket were used in the forward kinematic equation for the actual and virtual lengths, the distance from the boom hinge was $345.93 \mathrm{~cm}$ in the $\mathrm{x}$-direction and $-18.61 \mathrm{~cm}$ in the $\mathrm{y}$-direction in the actual angle measurement. The distance from the boom hinge was $336 \mathrm{~cm}$ in the $\mathrm{x}$-direction and $-6 \mathrm{~cm}$ in the $y$-direction in the virtual angle measurement. Thus, there was $8.93 \mathrm{~cm}$ difference in the $\mathrm{x}$-direction and a $12.04 \mathrm{~cm}$ difference in the y-direction. When the distance was directly measured, the actual distance in the $\mathrm{x}$ direction was $345 \mathrm{~cm}$, which resulted in a difference of $9 \mathrm{~cm}$ from the virtual measurement.

This performance evaluation shows that if the angle measurement is improved, the predictability of the actual equipment configuration can also be significantly improved. Considering that the specification requires that the permitted error be $3 \mathrm{~cm}$ (Ministry of Environment 2014), the capability of angle measurement still needs improvement for actual practice. Therefore, the angle measurement needs further study to gain the level of precision required in the specification.

\section{Conclusions}

This study applied a BIM technology to an earthwork operation. This approach was unique in that the BIM technology was implemented in an undefined process of the earthwork operation. The study provided a 3D graphic simulation environment where the virtual equipment configuration in the 3D earthwork BIM was synchronized with the actual equipment configuration during excavation work. A prototype of the 3D earthwork BIM was developed by integrating software and hardware. Digital maps represented the current and planned ground surfaces. Based on the digital maps, the prototype simulated the equipment configuration in a $3 \mathrm{D}$ digital space.

The prototype of the 3D earthwork BIM was tested during real excavation work. The field experiment demonstrated that the 3D earthwork BIM could synchronize the virtual equipment configuration with the actual equipment configuration. Although there is a need to improve the accuracy, the field experiment proved that the prototype can be further developed for a machine guidance system in the earthwork operation. When actually applied to the earthwork operation, the views of the deformation of the ground surface can provide information to the equipment operator about the current depth and the planned depth of the excavation. Then, equipment operators can improve the effectiveness of their excavation work utilizing the information from the 3D earthwork BIM.

This paper presents the first step of the process of applying BIM technology to excavation work. When fully developed, the 3D earthwork BIM can significantly improve the excavation work in construction operations. Considering that earthwork usually has a high impact on the overall construction budget, the use of the 3D earthwork BIM will greatly help in planning and executing the earthwork operations. That is, the information from the 3D earthwork BIM can be utilized for managerial functions. For example, (1) productivity can be measured for individual equipment operator; (2) the number of construction equipment that is needed can be estimated; (3) excavation costs can be reduced due to the more organized approach to planning the work; and (4) a virtual environment can be developed for training equipment operators. These added values for using the developed 3D earthwork BIM in the construction process justify its development.

In future work, the 3D earthwork BIM technology can be further developed as a machine guidance system. Such a system can enhance data management and functionality by assisting equipment operators. With improvements in accuracy and functionality, the 3D earthwork BIM can be extended to include other construction equipment, such as bulldozers and motor graders. Also, for the sake of experimental testing, the 3D earthwork BIM was applied to a flat ground surface in the field experiment. 
The digital map had the same elevation across the excavation site. However, the 3D earthwork BIM needs to be tested in differently shaped geographical terrains. Therefore, future studies should apply and test the 3D earthwork BIM in more complicated geographical terrains to improve its applicability and use in the earthwork operation.

\section{Acknowledgements}

This research was supported by a grant (16SCIPB07969003) from Smart Civil Infrastructure Research Program funded by Ministry of Land, Infrastructure and Transport (MOLIT) of Korea government and Korea Agency for Infrastructure Technology Advancement (KAIA).

\section{References}

Azar, E. R.; Feng, C.; Kamat, V. R. 2015. Feasibility of inplane articulation monitoring of excavator arm using planar marker tracking, Journal of Information Technology in Construction (ITcon) 20: 213-229.

Azhar, S. 2011. Building information modeling (BIM): Trends, benefits, risks, and challenges for the AEC industry, Leadership and Management in Engineering 11(3): 241-252. https://doi.org/10.1061/(ASCE)LM.1943-5630.0000127

Bedrick, J.; Davis, D. 2012. Aligning LOD, LoD and OEM into a project collaboration framework, Journal of Building Information Modeling, 25-26.

Bluetooth SIG Inc. 2016. Adopted specifications [online], [cited 10 Oct 2016]. Available from Internet: https://www.bluetooth.com/specifications/adopted-specifications

Burrough, P. A.; Mcdonnell, R. A.; Mcdonnell R.; Lloyd, C. D. 2015. Principles of geographical information systems. Oxford University Press.

Ministry of Environment. 2014. Standard specification for water and wastewater construction. Korea Governement.

Groover, M. P. 1986. Industrial robotics: technology, programming, and applications. McGraw-Hill.

Jo, J. J.; Ju, Y. D.; Kim, S. M.; Seo, H. J. 2012. Applications and future study of earthwork BIM (Building Information Modeling), in Korea Institute of Building Information Modeling Annual Conference, 2012, Seoul, Korea.

Kim, T. H.; Lee, C. S. 2014. A survey of Building Information Modeling in domestic public construction on actual case, in Proceedings of Korean Institute of Construction Engineering and Management, 2014. Student presentation, 247-251.

Lee, S. S.; Lee, M. J.; Jeong, J. W.; Seo, J. W. 2014. Design of flexible BIM system for alignment-based facility, Journal of Korean Society of Civil Engineers 34(2): 677-685.

https://doi.org/10.12652/Ksce.2014.34.2.0677

Leica Geosystems. 2016. Leica iCON iXE3 - 3D system [online], [cited 10 Oct 2016]. Available from Internet: http://leica-geosystems.com/products/machine-controlsystems/excavator/leica-icon-ixe3---3d-system.

Moon, S. W. 2015. Developing a 3D BIM for earthwork construction, in The $6^{\text {th }}$ International Conference on Construction Engineering and Project Management, 2015, Busan, Korea, 245-247.

National Geographic Information Institute (NGII). 2015. National Geographic Information Institute GNSS data service [online], [cited 10 Oct 2016]. Available from Internet: http://gnss.ngi.go.kr/

Prolec Ltd. 2016. Machine control: ProGrade [online], [cited 10 Oct 2016]. Available from Internet: http://www.prolec. co.uk/en/what-we-do/products/prograde/

Seo, J. W.; Lee, H. J.; Cassule, L.; Moon, S. W. 2015. Machine guidance based site control technology (SCT) for earthwork equipment fleet, in Proceedings of the $32^{\text {nd }}$ International Symposium on Automation and Robotics in Construction and Mining (ISARC 2015), 2015, Oulu, Finland, 455-459.

Seo, J. W.; Lee, S. S.; Kim, J. H.; Kim, S. K. 2011. Task planner design for an automated excavation system, Automation in Construction 20(7): 954-966. https://doi.org/10.1016/j.autcon.2011.03.013

Sharma, M.; Paige, G. B.; Miller, S. N. 2010. DEM development from ground-based LiDAR data: A method to remove non-surface objects, Remote Sensing 2: 2629-2642. https://doi.org/10.3390/rs2112629

Topcon. 2016. Mass excavation [online], [cited 10 Oct 2016]. Available from Internet: https://www.topconpositioning. com/construction/mass-excavation

World Meteorological Organization (WMO). 2012. Technical material for water resources assessment. WMO Publication.

Yamamoto, H.; Moteki, M.; Shao, H.; Ootuki, T.; Kanazawa, H.; Tanaka, Y. 2009. Basic technology toward autonomous hydraulic excavator, in The $26^{\text {th }}$ International Symposium on Automation and Robotics in Construction (ISARC 2009), 2009, Austin, Texas, U.S., 288-295.

Sungwoo MOON. He is currently a professor in the Department of Civil and Environmental Engineering, Pusan National University, South Korea. He earned his PhD in the Civil and Environmental Engineering, North Carolina State University with a dissertation: "Construction Automation: Effectiveness of a Virtual Human-Machine Interface for Large-Scale Manipulator Control". His research interests focus on construction automation and process improvement through the application of information and communication technologies. He is currently working on the development of a construction machine guidance system using the Building Information Modeling (BIM) technique. The aim in this endeavor is to provide a user-friendly control environment in which the equipment operator can access to information for machine control and improve productivity during earthwork.

Jongwon SEO. He is a Professor in the Department of Civil and Environmental Engineering at Hanyang University, South Korea. He holds Professional Engineer's license in the state of California, U.S., and a member of American Society of Civil Engineers (ASCE), Korean Society of Civil Engineers (KSCE), Korea Institute of Construction Engineering and Management (KICEM), and Architectural Institute of Korea, etc. Currently, he is the leader of a research consortium named "Fleet management for construction equipment and Smart construction technology using ICT" funded by Ministry of Land, Infrastructure and Transport (MOLIT) of Korean government. His research interests include (1) Automated earthmoving system; (2) Fully- integrated construction technology; (3) Graphical control of large equipment in unstructured environments; (4) Integrating design and construction for highway projects;

(5) Simulation and visualization for infrastructure construction; (6) Virtual reality system for construction safety. 